\title{
Commentary to: Prospective comparative study on the effects of lidocaine on urodynamic and sensory parameters in bladder-pain syndrome
}

\author{
Annika Taithongchai ${ }^{1}$ \\ Received: 14 February 2019 / Accepted: 5 March 2019 / Published online: 13 April 2019 \\ (C) The International Urogynecological Association 2019
}

The above-named article assesses the effects of lidocaine on perceived pain and urodynamic parameters in bladder-pain syndrome (BPS). Twenty-four women with BPS were assessed, their diagnosis being based on symptoms and cystoscopic and urodynamic findings. Sixteen women were randomised to have $20 \mathrm{ml}$ of intravesically administered $2 \%$ alkalinised lidocaine, and eight women had $20 \mathrm{ml}$ of normal saline. Women were blinded to their allocation arm; pain scores, maximum cystometric capacity (MCC) and urodynamic sensation volumes were reported for pre- and post-instillation. The hypothesis was that lidocaine would distinguish between central and peripheral mechanisms of action for BPS, suggesting that it is a condition driven by a combination of both; assuming that failure to respond to lidocaine instillation suggests a more central sensitivity syndrome rather than peripherally mediated disease [1].

They found a significant increase in MCC and all sensation volumes on urodynamics post-lidocaine treatment, as well as a reduction in pain. However five of 16 in the lidocaine arm did not respond in any aspect; all five had a worse quality of life (QoL) and a tendency towards central sensitivity syndromes based on their King's Health Questionnaire (KHQ) and the Central Sensitisation Inventory (CSI) questionnaire.

The main limitation of their article is patient selection: ten patients withdrew from the study due to intolerable pain during urodynamics, which may significantly bias results, as the starting cohort number was small. However, their strict exclusion criteria meant they could fairly confidently be certain that patients had an accurate diagnosis of BPS and not another extra-urinary cause for their pain. Their study adds to our understanding of BPS mechanisms, strongly suggesting a clearer focus is needed during research on sub-grouping patients into central or peripherally dominant BPS. This would allow for the development of individualised treatment for women with this challenging spectrum of disease. Routine use of lidocaine with urodynamics in daily clinical practice, when investigating potential BPS, is yet unproven.

\section{Compliance with ethical standards}

Conflicts of interest None.

\section{References}

1. Offiah I, Dilloughery E, McMahon SB, O'Reilly BA. Prospective comparative study of the effects of lidocaine on urodynamic and sensory parameters in bladder pain syndrome. Int Urogynecol J. 2019 Mar 14. https://doi.org/10.1007/s00192-019-03892-2.

Publisher's note Springer Nature remains neutral with regard to jurisdictional claims in published maps and institutional affiliations.
Annika Taithongchai

Annika.taithongchai@nhs.net

1 Croydon University Hospital, 530 London Road, Croydon CR0 5EL, UK 